\title{
Simultaneous Determination of Iron and Cobalt using Spectrophotometry after Catanionic Mixed Micellar Cloud Point Extraction Procedure
}

\author{
RAVI KUMAR KAKITHA ${ }^{1}$, SHYAMALA PULIPAKA ${ }^{1 *}$ and DEVA H PURANAM ${ }^{1,2}$ \\ 'Department of PNCO, School of Chemistry, Andhra University, Visakhapatnam-530 003, \\ Andhra Pradesh, India. \\ ${ }^{2}$ Global Quality Investigations, Mylan, Canonsburg 15317, PA, United States of America. \\ ${ }^{*}$ Corresponding author E-mail: shyamalapulipaka06@gmail.com
}

http://dx.doi.org/10.13005/ojc/360622

(Received: August 04, 2020; Accepted: November 23, 2020)

\begin{abstract}
A new preconcentration method which utilises a mixture of cationic and anionic surfactants for separation and spectrophotometric determination of iron and cobalt simultaneously has been developed. The metal ions, iron and cobalt were complexed with thiocyante. The hydrophobic complexes of iron and cobalt were then extracted into catanionic mixed micelles of cetyltrimethylammonium bromide (CTAB) and sodium dodecyl sulphate (SDS). Different parameters like concentration of $\mathrm{HCl}$, concentration of thiocyanate, concentrations of the surfactants (CTAB and SDS), equilibration temperature and time were studied to get maximum efficiency. The linear ranges of $\mathrm{Fe}^{3+}$ and $\mathrm{Co}^{2+}$ were found to be $0.139-0.838 \mu \mathrm{g} \mathrm{mL}^{-1}$ and $5.89-35.4 \mu \mathrm{g} \mathrm{mL}^{-1}$, respectively the detection limits obtained were $1.54 \mathrm{ng} \mathrm{mL}^{-1}$ and $6.18 \mathrm{ng} \mathrm{mL}^{-1}$. The developed procedure has been employed for the retrieval of $\mathrm{Fe}^{3+}$ and $\mathrm{Co}^{2+}$ in water samples successfully (tap water and sea water). $98-107 \%$ recoveries were obtained.
\end{abstract}

Keywords: Cloud point extraction, Catanionic mixed micelles, Iron and Cobalt.

\section{INTRODUCTION}

Iron and Cobalt are the most important metals in biological systems, as they are the constituent elements in haemoglobin and vitamin $B_{12}$ (Cyanocobalamin). The deficiency of these analytes might lead to deadly diseases like anaemia while the high levels of iron might cause diseases like thalassemia. Excess of cobalt may result in cardiomyopathy or vasodilation in human beings. It is therefore important to determine the levels of iron and cobalt accurately.

Direct determination of these metals in water is a complex process, because of their very low concentrations and the high interferences from other components in the solution. Hence, reducing the matrix effects is an important task prior to their determination. The cloud point extraction is an environmentally favourable technique which follows green chemistry principles for extraction. When the surfactants are heated they separate into two different

This is an Open Access article licensed under a Creative Commons license: Attribution 4.0 International (CC- BY). Published by Oriental Scientific Publishing Company @ 2018

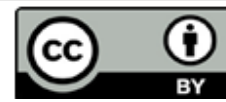


phases at a particular temperature called cloud point temperature, the surfactant abundant phase and the water phase. solutes/metal ions can be removed into the surfactant phase. In cloud point extraction procedure, the two important factors for selection of surfactants is that the cloud point temperature should be close to room temperature and the other is extraction efficiency. The extraction of compounds is due to the hydrophobic and electrostatic interactions with the micelles. Maximum extraction efficiency is achieved by using two surfactants.

The method has been used for the extraction of metal complexes with ligands like APDC (ammonium pyrrolidine dithiocarbamate) ${ }^{1-4}$, 8-HQ (8-hydroxyquinoline) $)^{5,6}, 2-\mathrm{GB}$ (2-guanidino benzimidazole) $)^{7}$, TAN (1-(2-thiazolylazo)-2naphthol) $)^{8,9}$, PMBP (1-phenyl-3-methyl-4-benzoyl5-pyrazolone) ${ }^{10}, \mathrm{PHBI}$ (2-phenyl-1H-benzo[d] Imidazole) ${ }^{11}$, MPMP (2-[(2-mercaptophenylimino) methyl]phenol) ${ }^{3}$, Me-BTABr (2-[2-(6-methylbenzothiazolylazo)]-4-bromophenol) ${ }^{12}$, MPKO (methyl-2-pyridylketone oxime) $)^{13}$, anthralin (1, 8-dihydroxyanthrone) $)^{14}$ and ACDA (2-aminocyclopentene-1-dithiocarboxylic acid) ${ }^{15}$.The addition of salts also influences the cloud point where the temperature decreases by salting out effect ${ }^{16-18}$. The retrieval of iron and cobalt in different matrices by cloud point extraction was reported in literature using expensive instruments like atomic absorption spectrometry with graphite furnace (GFAAS) ${ }^{12,19}$, inductively-coupled plasma with OES (ICP-OES) $)^{5,6}$.

In this paper we report the spectrophotometric determination of $\mathrm{Fe}^{3+}$ and $\mathrm{Co}^{2+}$ metal ions simultaneously in the presence of thiocyanate ligand using catanionic mixed micelles of CTAB and SDS. The surfactant phase of catanionic mixed micelles formed from CTAB and SDS have both positive and negative entities of the surfactants ${ }^{20}$, which resulted in a strong synergistic effect(indicated by a negative interaction parameter between the two surfactants $(\beta)^{21,22}$ thereby increasing the efficiency of the extraction process. The factors affecting the extraction were optimised to get maximum efficiency and the developed system was used for the calculation of $\mathrm{Fe}^{3+}$ and $\mathrm{Co}^{2+}$ in different real samples of water.

\section{MATERIALS AND METHODS}

\section{Instrumentation}

A Shimadzu spectrophotometer was used for measuring absorbance. A systronics digital $\mathrm{pH}$ meter 335 was used for all pH measurements.

\section{Reagents and solutions}

Analytical grade reagents were used. Sigma-Aldrich make Cetyltrimethylammonium bromide, CTAB and (Sodium dodecyl sulfate, SDS) were used. Aqueous solutions of $10 \%(w / v)$ CTAB and $10 \%(\mathrm{w} / \mathrm{v})$ SDS were made. Standard solutions of $\mathrm{Fe}^{3+}$ and $\mathrm{Co}^{2+}$ were made from ammonium ferric sulphate and cobaltous chloride respectively which are taken as stock solutions. An aqueous solution of the ligand, sodium thiocyante ( $\mathrm{NaSCN}$ ) obtained from Lobachemie, India. $5 \mathrm{~mol} \mathrm{~L}^{-1}$ solution of NaSCN was made.

\section{Experimental procedure}

In a graduated test tube, $0.15 \mathrm{~mL}$ of concentrated hydrochloric acid and standards of corresponding concentrations of analytes were added followed by $1.1 \mathrm{~mL}$ of $5 \mathrm{~mol} \mathrm{dm}^{-3} \mathrm{NaSCN}$, $1.1 \mathrm{~mL}$ of $10 \%(\mathrm{w} / \mathrm{v})$ CTAB and $50 \mu \mathrm{L}$ of $10 \%(\mathrm{w} / \mathrm{v})$ SDS and made up to $10 \mathrm{~mL}$ with Milli-Q water. The mixture was then heated to $50^{\circ} \mathrm{C}$ for 15 minutes. After heating, two phases were observed. Phase separation was obtained completely after reducing the temperature of the system during a period of one hour. In this method surfactant rich phase was observed at the top and bulk aqueous phase was observed at bottom. The non-surfactant phase was decanted. Methanol was used to dissolve the surfactant phase containing the metal ions and absorbance was recorded at wavelengths of maximum absorbance $\left(502 \mathrm{~nm}\right.$ for $\mathrm{Fe}^{3+}-\mathrm{SCN}-$ complex and $618 \mathrm{~nm}$ for $\mathrm{Co}^{2+}-\mathrm{SCN}-$ complex).

\section{RESULTS \& DISCUSSION}

To get maximum efficiency of the method, each reagent concentration was changed and keeping all other reagents constant and optimizing each reagent at a time.

\section{Variation of \% (v/v) of $\mathrm{HCl}$}

Three types of mineral acids $\left(\mathrm{H}_{2} \mathrm{SO}_{4}, \mathrm{HNO}_{3}\right.$ and $\mathrm{HCl}$ ) were chosen for the initial study of the system. The recoveries of the analytes show that 
hydrochloric acid is the best acid for the extraction of these metal complexes simultaneously. The effect of $\mathrm{HCl}$ concentration was varied from $0 \%(\mathrm{v} / \mathrm{v})$ to $10 \%$ $(\mathrm{v} / \mathrm{v})$. The extraction increases up to $1.5 \%(\mathrm{v} / \mathrm{v})$ of $\mathrm{HCl}$ and thereafter decreases. Fig. 1 shows that the percentage concentration of $\mathrm{HCl}$ for the simultaneous extraction of $\mathrm{Fe}^{3+}$ and $\mathrm{Co}^{2+}$ is $1.5 \%(\mathrm{v} / \mathrm{v})$.

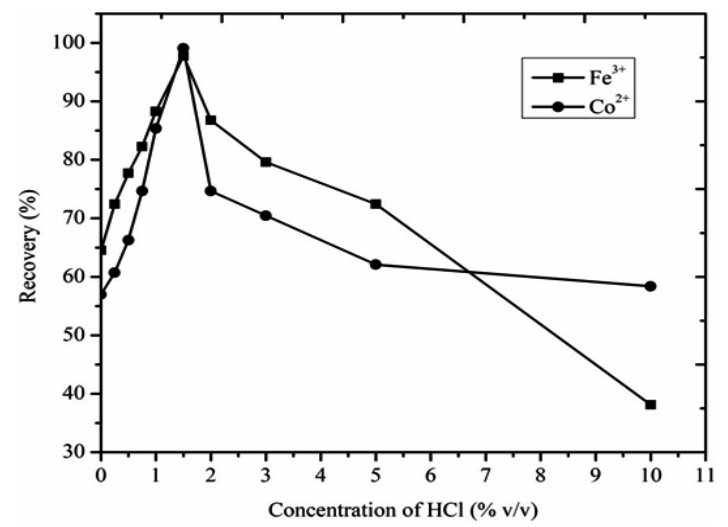

Fig. 1. Plot of recovery versus percentage concentration of $\mathrm{HCl}$. Conditions: $0.55 \mathrm{~mol} \mathrm{~L}^{-1}$ of SCN-, $1.1 \%$ CTAB (w/v), $0.05 \%$ SDS $(w / v), 50^{\circ} \mathrm{C}$ of equilibration temperature, 15 min of equilibration time

\section{Variation of the amount of SCN}

The concentration of the monodentate ligand, SCN- selected for complex formation with analytes $\mathrm{Fe}^{3+}$ and $\mathrm{Co}^{2+}$ was varied in the range $(0.1$ to 0.6$) \mathrm{mol} \mathrm{L}^{-1}$. The recoveries increase up to 0.55 mol L-1 concentration of SCN- and then decrease for both the metals. Therefore, $0.55 \mathrm{~mol} \mathrm{~L}^{-1}$ of $\mathrm{SCN}$ - was used for the rest of the study (Figure 2).

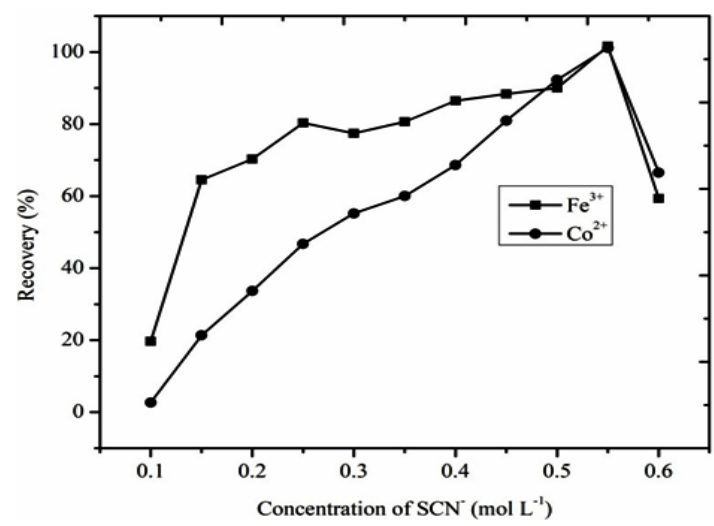

Fig. 2. Variation of amount of SCN-. Conditions: $1.5 \%(v / v)$ of $\mathrm{HCl}, 1.1 \% \mathrm{CTAB}(\mathrm{w} / \mathrm{v}), 0.05 \% \mathrm{SDS}(\mathrm{w} / \mathrm{v}), 50^{\circ} \mathrm{C}$ of equilibration temperature, $15 \mathrm{~min}$ of equilibration time

\section{Variation of $\%(w / v)$ of CTAB}

Percentage of CTAB was changed from
(0.1 to 1.2$) \%(w / v)$ and recovery of $\mathrm{Fe}^{3+}$ and $\mathrm{Co}^{2+}$ was studied. The metal retrieval increases up to $1.1 \%$ $(\mathrm{w} / \mathrm{v})$ of CTAB and then decreases (Fig. 3). 1.1\% $(w / v)$ CTAB was fixed for the rest of the study.

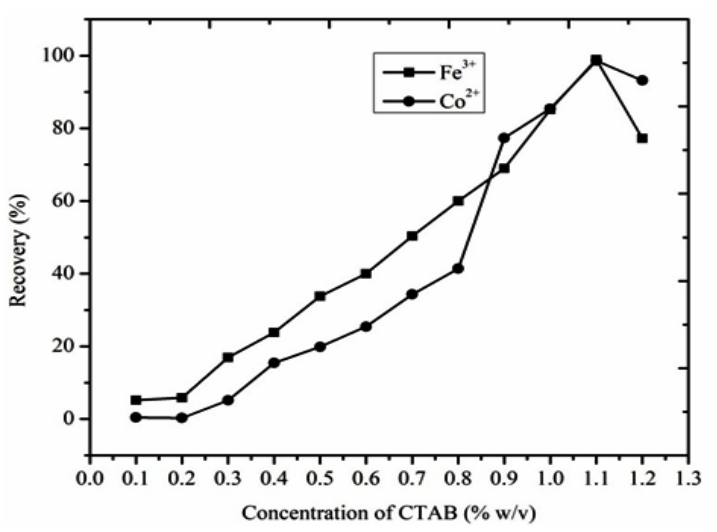

Fig. 3. Plot of recovery versus $\%(w / v)$ CTAB. Conditions: $1.5 \%(\mathrm{v} / \mathrm{v})$ of $\mathrm{HCl}, 0.55 \mathrm{~mol} \mathrm{~L}^{-1}$ of SCN-, $0.05 \%(\mathrm{w} / \mathrm{v})$ of SDS, $50^{\circ} \mathrm{C}$ of equilibration temperature, $15 \mathrm{~min}$. of equilibration time

\section{Optimization of $\%(w / v)$ of SDS}

SDS concentration was varied from $(0-0.1) \%(w / v)$ to get maximum recovery. The extraction of analytes increases till $0.05 \%(w / v)$ of SDS and decreases thereafter (Fig. 4). Therefore, $0.05 \%$ SDS concentration was used for maximum extraction of $\mathrm{Fe}^{3+}$ and $\mathrm{Co}^{2+}$.



Fig. 4. Variation of $\%(w / v)$ of SDS. Conditions: $\mathrm{HCl}=1.5 \%$ $(\mathrm{v} / \mathrm{v}), \mathrm{SCN}-=0.55 \mathrm{~mol} \mathrm{~L}^{-1}, \mathrm{CTAB}=1.1 \%(\mathrm{w} / \mathrm{v})$, equilibration temperature $=50^{\circ} \mathrm{C}$, incubation time $=15$ minutes

The metal extraction mechanism in for the mixed micellar system of CTAB and SDS can be explained by the following mechanism. The monodentate ligand, SCN- and anionic surfactant, SDS, form a negative metal complex which is then form ion-pair complex with protons from strong acids or positive surfactant CTAB. 


$$
\begin{aligned}
& \mathrm{M}^{\mathrm{n}+}+\mathrm{nL}^{-}+\mathrm{nDS}^{-} \longrightarrow\left[\mathrm{ML}_{\mathrm{n}}(\mathrm{DS})_{\mathrm{n}}\right]^{\mathrm{n}-} \\
& \text { Metal ligand complex } \\
& \left(\mathrm{L}=\mathrm{SCN}^{-}, \mathrm{Cl}^{-}\right) \\
& {\left[\mathrm{ML}_{\mathrm{n}}(\mathrm{DS})_{\mathrm{n}}\right]^{\mathrm{n}-}+\mathrm{nCTA}^{+} \longrightarrow\left[\mathrm{nCTA}^{+}\right]\left[\mathrm{ML}_{\mathrm{n}}(\mathrm{DS})_{\mathrm{n}}\right]^{\mathrm{n}-}} \\
& \text { Ion pair between } \\
& \text { complex and CTAB } \\
& {\left[\mathrm{ML}_{\mathrm{n}}(\mathrm{DS})_{\mathrm{n}}\right]^{\mathrm{n}-}+\mathrm{nH}^{+} \longrightarrow\left[\mathrm{nH}^{+}\right]\left[\mathrm{ML}_{\mathrm{n}}(\mathrm{DS})_{\mathrm{n}}\right]^{\mathrm{n}-}} \\
& \text { protons from }
\end{aligned}
$$

Optimization of incubation time and equilibration temperature

It is always advisable to have shortest incubation time and temperature close to room temperature along with maximum recovery of the method. In the present study the equilibration temperature was varied from 25 to $100^{\circ} \mathrm{C}$ and equilibration time was changed from 5 to 60 minutes. The optimum temperature was observed to be $50^{\circ} \mathrm{C}$ and optimum time was found to be $15 \mathrm{~min}$ respectively.

\section{Analytical figures of the method}

The analytical parameters of the developed method were determined. The observed linearity ranges of $\mathrm{Fe}^{3+}$ and $\mathrm{Co}^{2+}$ from the calibration graphs were found to be $0.139-0.838 \mu \mathrm{g} \mathrm{mL}^{-1}$ and 5.89-35.4 $\mu \mathrm{g} \mathrm{mL}^{-1}$, respectively. The equations obtained were $\mathrm{A}=0.532446\left[\mathrm{Fe}^{3+}\right]+0.004214$ and $\mathrm{A}=0.013357$ $\left[\mathrm{Co}^{2+}\right]+0.013000$ with correlation coefficients of 0.9990 and 0.9934 for $\mathrm{Fe}^{3+}$ and $\mathrm{Co}^{2+}$. The detection

\begin{tabular}{|c|c|c|c|c|c|c|}
\hline Analytes & Ligand & Surfactants & LOD & Technique & Matrix & References \\
\hline $\mathrm{Fe}, \mathrm{Co}$ and $\mathrm{Ni}$ & APDC & $\mathrm{TX}-114$ & $\begin{array}{c}19,5 \text { and } 11 \mu \mathrm{g} \mathrm{L}^{-1} \text { for } \\
\mathrm{Fe}, \mathrm{Co} \text { and } \mathrm{Ni}\end{array}$ & FIA-FAAS & $\begin{array}{l}\text { Waste, river, tap } \\
\text { and sea water. }\end{array}$ & [9] \\
\hline $\mathrm{Fe}$ & Ferron & $\mathrm{TX}-114$ & $1.7 \mu \mathrm{g} \mathrm{L}^{-1}$ & FI-FAAS & Water and milk & [42] \\
\hline Co & PAN & TX-114 & $0.6 \mu \mathrm{g} \mathrm{L}^{-1}$ & Spectrophotometry & Water samples & [14] \\
\hline Co & Without & PONPE 7.5 & $10 \mathrm{ng} \mathrm{L}^{-1}$ & ETAAS & $\begin{array}{l}\text { Drinking water } \\
\text { samples }\end{array}$ & {$[37]$} \\
\hline $\mathrm{Co}, \mathrm{Ni}$ & ACDA & $\mathrm{TX}-114$ & $\begin{array}{l}7.5 \text { and } 10 \mu \mathrm{g} \mathrm{L}^{-1} \\
\text { for } \mathrm{Co} \text { and } \mathrm{Ni}\end{array}$ & Spectrophotometry & $\begin{array}{c}\text { Natural and waste } \\
\text { water samples }\end{array}$ & [33] \\
\hline $\mathrm{Fe}, \mathrm{Co}$ & $\mathrm{SCN}-$ & CTAB and SDS & $\begin{array}{l}1.54 \text { and } 6.18 \mathrm{ng} \mathrm{mL}^{-1} \\
\text { for Fe and Co }\end{array}$ & UV-Vis Spectrophotometry & $\begin{array}{c}\text { Tap and sea } \\
\text { water samples }\end{array}$ & $\begin{array}{c}\text { Method developed } \\
\text { in this paper }\end{array}$ \\
\hline
\end{tabular}
limits for $\mathrm{Fe}^{3+}$ and $\mathrm{Co}^{2+}$ were as low as $1.54 \mathrm{ng} \mathrm{mL}^{-1}$ and $6.18 \mathrm{ng} \mathrm{mL}^{-1}$, respectively. The preconcentration factor and phase volume ratio of the method are 40 and 0.025 , respectively Table 1 . A comparison of the results obtained from the developed method with methods reported in literature for the retrieval of $\mathrm{Fe}^{3+}$ and $\mathrm{Co}^{2+}$ is given in Table 2 .

Table 1: Analytical parameters for the two metals

\begin{tabular}{ccc}
\hline Parameter & $\mathrm{Fe}^{3+}$ & $\mathrm{Co}^{2+}$ \\
\hline$\lambda_{\max }(\mathrm{nm})$ & 502 & 618 \\
Linear range $\left(\mu \mathrm{g} \mathrm{mL}^{-1}\right)$ & $0.13-0.84$ & $2.9-35.4$ \\
Correlation coefficient $\left(\mathrm{R}^{2}\right)$ & 0.9990 & 0.9934 \\
LOD $\left(\mathrm{ng} \mathrm{mL}^{-1}\right)$ & 1.54 & 6.18 \\
Preconcentration factor & 40 & 40 \\
Phase volume ratio & 0.025 & 0.025 \\
Extraction efficiency $(\%)$ & 98.26 & 100.76 \\
\hline
\end{tabular}

Table 2: List of the details of the present method and previous methods

Validation of the method and analysis of real samples

was employed for the simultaneous determination of The developed cloud point extraction $\quad \mathrm{Fe}^{3+}$ and $\mathrm{Co}^{2+}$ in different water samples. 92-102\% method using CTAB and SDS mixed micellar system

spike recoveries were found Table 3.

Table 3: Recovery values of $\mathrm{Fe}^{3+}$ and $\mathrm{Co}^{2+}$ in water samples along with spike recoveries

\begin{tabular}{ccccccc}
\hline Samples & \multicolumn{2}{c}{ Spiked $\left(\mu \mathrm{g} \mathrm{mL}^{-1}\right)$} & \multicolumn{2}{c}{ Detected $\left(\mu \mathrm{g} \mathrm{mL} \mathrm{m}^{-1}\right)$} & \multicolumn{2}{c}{$\operatorname{Recovery}(\%)$} \\
\hline & $\mathrm{Fe}^{3+}$ & $\mathrm{Co}^{2+}$ & $\mathrm{Fe}^{3+}$ & $\mathrm{Co}^{2+}$ & $\mathrm{Fe}^{3+}$ & $\mathrm{Co}^{2+}$ \\
Tap water & - & - & $0.0906 \pm 0.0023$ & $1.733 \pm 0.06$ & - & - \\
& 0.419 & 11.79 & $0.519 \pm 0.02$ & $13.84 \pm 0.297$ & $102.24 \pm 4.89$ & $102.69 \pm 2.07$ \\
& 0.698 & 23.57 & $0.783 \pm 0.04$ & $25.62 \pm 1.09$ & $99.2 \pm 5.65$ & $101.34 \pm 4.36$ \\
Sea water & - & - & $\mathrm{ND}$ & $\mathrm{ND}$ & - & - \\
& 0.419 & 11.79 & $0.403 \pm 0.02$ & $11.27 \pm 0.36$ & $96.18 \pm 5.18$ & $95.59 \pm 3.05$ \\
& 0.698 & 23.57 & $0.646 \pm 0.03$ & $21.69 \pm 1.02$ & $92.55 \pm 4.65$ & $92.02 \pm 4.31$
\end{tabular}




\section{CONCLUSION}

A new cloud point extraction method based on catanionic mixed micelles of CTAB and SDS for the preconcentration of $\mathrm{Fe}^{3+}$ and $\mathrm{Co}^{2+}$ and their determination simultaneously using spectrophotometry in different water samples in the presence of thiocyanate as ligand was developed. This new method is much simple and accurate and for the determination of $\mathrm{Fe}^{3+}$ and
$\mathrm{Co}^{2+}$ at $\mathrm{ng} \mathrm{mL}^{-1}$ level.

\section{ACKNOWLEDGMENT}

This research did not receive any specific grant from funding agencies in the public, commercial, or not-for-profit sectors.

\section{Conflicts of Interest}

The authors declare no conflict of interest.

\section{REFERENCES}

1. Giokas, D. L.; Paleologos, E. K.; TzouwaraKarayanni, S. M.;\&Karayannis, M. I. J. Anal. At. Spectrom., 2001, 16, 521-526.

2. Paleologos, E. K.; Giokas, D. L.; TzouwaraKarayanni, S. M.; \&Karayannis, M. I. Anal. Chim. Acta., 2002, 458, 241-248.

3. George, L. D.; Clésia, C. N.; Ana, R. A. N.; Marco, A. Z. A.; \& Joaquim, A. N. Microchem J., 2006, 82, 189-195.

4. Dimosthenis, L. G.; Evangelos, K. P.; \& Miltiades, I. K. Anal. Bioanal. Chem., 2002, 373, 237-243.

5. Francisco, L. F. S.; Wladiana, O. M.; \& Gisele, S. L. Anal., 2015, 7, 9844-9849.

6. Lingling, Z.; Shuxian, Z.; Keming, F.; Zhaosheng, Q.; \& Jianrong, C. J. Hazard. Mater., 2012, 239-240, 206-212.

7. Dallali, N.; Zahedi, M. M.; \& Yamini, Y. Sci Iran., 2007, 14, 291-296.

8. Ghulam, A. K.; Tasneem, G. K.; Jameel, A. B.; Sirajuddin., Hassan, I. A.; Abdul, Q. S.; Hafeez, R. S.; Nida, F. K.; \& Sham, K. W. J. Aoac Int., 2010, 93, 1589-1594.

9. Sidnei, G. S.; Pedro, V. O.; Fábio, R. P. R. J Brazil Chem Soc., 2010, 21, 234-239.

10. Pei, L.; Hongbo, S.; Zhimei, S. J. Colloid Interface Sci., 2006, 304, 486-490.
11. Ghaedi, M.; Shokrollahi, A.; Niknam, K.; Soylak, M. Sep Sci Technol., 2009, 44, 773-786.

12. Valfredo, A. L.; Robson, S. F.; \& Bruno, O. M. Sep. Purif. Technol., 2007, 54, 349-354.

13. Ghaedi, M.; Shokrollahi, A.; Ahmadi, F.; Rajabi, H. R.; Soylak, M. J. Hazard. Mater., 2008, 150, 533-540.

14. Assadollah, B.; Saeed, B.; \& Mina, R. Microchem J., 2012, 100, 66-71.

15. Safavi, A.; Abdollahi, H.; Hormozi, N. M. R.; Kamali, R. Spectrochimi Acta A., 2004, 60, 2897-2901.

16. Tayyebeh, M.; Abbas, A.; Afrouz, M. Talanta., 2007, 71, 610-614.

17. Alaa, S. A.; Mohammed, A. K. Talanta, Y. M. RSC Adv., 2015, 5, 52095-52100.

18. Wael, I. M.; Al-Ahmad, Z. A.; Mohamed, M. H. Anal. Methods., 2013, 5, 5234-5240.

19. Raúl, A. G.; José, A. G.; Roberto, O.; Luis, D. M.; Soledad, C. Talanta., 2008, 76, 669-673

20. Sylvain, P.; Michael, G. J Colloid Interface Sci., 2009, 337, 472-484.

21. Sara, B. L.; Xiang, W.; Mohammad, R. I.; Emily, J.D.; Douglas, S. E. Phys. Chem.Chem. Phys., 2009, 11, 9315-9325.

22. Shakerian, F.; Dadfarnia, S.; Haji Shabani, A. M. JIran Chem Soc., 2009, 6, 594-601. 